\title{
Antimicrobial and Antiviral Screening of Novel Indole Carboxamide and Propanamide Derivatives
}

\author{
Süreyya Ölgen ${ }^{\mathrm{a}, *}$, Nurten Altanlar ${ }^{\mathrm{b}}$, Ersin Karataylı $^{\mathrm{c}}$, and Mithat Bozday ${ }^{\mathrm{c}}$ \\ a Department of Pharmaceutical Chemistry, Faculty of Pharmacy, Ankara University, 06100, \\ Tandogan, Ankara, Turkey. Fax: +90 (312) 2131081. \\ E-mail: olgen@pharmacy.ankara.edu.tr \\ b Department of Pharmaceutical Microbiology, Faculty of Pharmacy, Ankara University, \\ 06100, Tandogan, Ankara, Turkey \\ c Institute of Hepatology, Ankara University, Ankara, Turkey \\ * Author for correspondence and reprint requests \\ Z. Naturforsch. 63c, 189-195 (2008); received August 15/September 24, 2007
}

A few series of indole derivatives were screened for antimicrobial, antifungal and antiHBV activities. The compounds were tested for their in vitro antibacterial activity against Staphylococcus aureus, Bacillus subtilis, Escherichia coli and for their antifungal activity against Candida albicans using a disc diffusion method, which measures the diameter of the inhibition zone around a paper disc soaked in a solution of the test compounds. The antimicrobial activity results showed that all compounds are as a active as the standard compound ampicillin against Staphylococcus aureus. It was also found that indole carboxamide derivatives, substituted at 3-position with several benzyl groups, showed better inhibition of Bacillus subtilis than their congeners substituted at 2-position. Activity patterns of the compounds against Escherichia coli and Staphylococcus aureus were found slightly different by the same method. In this case, there was no correlation between structure and activity of the compounds. The antifungal activity of carboxamide derivatives was found higher compared to that of the propanamide derivatives. The minimum inhibitory concentration (MIC) values of some indole derivatives were also determined by the tube dilution technique. The MIC values of the compounds were found nearly 20- to 100 -fold smaller compared to the standard compounds ciprofloxacin and ampicillin $(1.56-3.13 \mu \mathrm{g} / \mathrm{ml}$ and $1.56-12.5 \mu \mathrm{g} / \mathrm{ml}$, respectively) against Staphylococcus aureus, Bacillus subtilis and Escherichia coli. The MIC values of the tested compounds showed that these are better inhibitors for Candida albicans. Indole derivatives were screened by the anti-HBV susceptibility test. No compound showed good inhibition against the $\mathrm{HBV}$ virus.

Key words: Indole Derivatives, Antibacterial and Antifungal Activity, Inhibition of HBV

\section{Introduction}

Indole derivatives have been found to possess a wide range of biological activities such as anticonvulsant, antidepressant, antihistamine, antitubercular, cardiovascular, antidiabetic, anti-inflammatory, anthelmintic, antiallergic, antiviral, antifungal and antimicrobial activities (Mehta et al., 2005).

A lot of simple indole derivatives was reported as antimicrobial and antifungal agents in several studies. Among them ethyl-3-indolylacrylate, 5bromo-3-(2-cyanovinyl)indole and 3-(2-nitrovinyl)indole were found active against a wide variety of microorganisms. Haloindoles were also found highly active at concentrations of $10-100 \mu \mathrm{g} / \mathrm{ml}$ (Whitehead and Whitesitt, 1974). Another study demonstrated that some 3-acyl-4,7-dihydroxy indoles have antibacterial properties against Escheri- chia coli and Streptococcus pyogenes (Malesani et al., 1975). 1-Morpholino-3-carbethoxy-5-hydroxy2-methylindole was reported to be highly active against Escherichia coli and Bacillus cirroflagellosus (Donawade and Gadaginamath, 2005). 1-(4Phenyl) and (1-naphthyl-4H-1,2,4-triazole-5-thion3-yl)indoles exhibited strong antibacterial and antifungal activities (Tsotinis et al., 1997). Some indole-containing derivatives of thiosemicarbazide and their cyclic 1,2,4-triazole and 1,3,4-thiadiazole analogues were found to be selective antimicrobial and antifungal agents (Varvaresou et al., 2000). Antimicrobial activities of several indole derivatives fused with heterocyclic compounds were also investigated. Among them, 4H-pyrano[2,3-f]indole, benzotetrahydrocyclohept[1,2- $b]$ indole, and 1-triazolylethylbenz $[\mathrm{g}]$ indole derivatives showed considerable antimicrobial activities (Macchia 
et al., 1996; Gadaginamath and Kavali, 1999; Bhovi and Gadaginamath, 2005).

Some indole compounds also exhibited a remarkable potential of antiviral activity. 5-Chloro-3(phenylsulfonyl)indole-2-carboxamide derivatives were reported as HIV-1 reverse transcriptase inhibitors with nanomolar $\mathrm{IC}_{50}$ values (Williams et al., 1993). An indole-containing non-nucleoside reverse transcriptase inhibitor, delavirdine (Rescriptor $^{\circledR}$ ), was approved as a commercial antiHIV drug (Romero et al., 1996). N-Alkyl-substituted indolocarbazoles were found to be potent inhibitors of human cytomegalovirus in nanomolar ranges (Slater et al., 2001). 6-Bromo-6-hydroxy$1 \mathrm{H}$-indole-3-carboxylate derivatives were reported as anti-influenza virus inhibitors (Zhao et al., 2004). Some tetracyclic indole derivatives showed anti-HCV activity with $\mathrm{IC}_{50}$ values below $5 \mu \mathrm{M}$ (Conte et al., 2006). Some oxoindole derivatives were found to be potent HIV-1 non-nucleoside reverse transcriptase inhibitors (Jiang et al., 2006). Recently, $N$-morpholinoacetyl-2-phenyl-indole-6carboxylic acid was determined as potent inhibitor of subgenomic hepatitis $\mathrm{C}$ virus replication with an $\mathrm{IC}_{50}$ value of $0.127 \mu \mathrm{M}$ (Harper et al., 2005). Another research group also reported the compound $\mathrm{N}$-methyl-2-phenyl-3-cyclohexyl-indole-6-carboxylic acid as allosteric inhibitor of the HCV virus ( $\left.\mathrm{IC}_{50} 0.009 \mu \mathrm{M}\right)$ (Beaulieu et al., 2006).

Hepatitis B virus (HBV) is the major cause of acute and chronic hepatitis which could lead to hepatocellular carcinoma. The wide prevalence of chronic HBV infection together with the lack of an effective drug available for the treatment warrants the search for novel therapeutic agents against the virus (Tan et al., 2006). Current approaches to the development of a therapy for HBV infection are centered mainly on nucleoside analogues targeting HBV reverse transcriptase/ polymerase (Ying et al., 2003). The major problem using nucleoside analogues as therapeutic agents is the emergence of resistant viruses. Various nonnucleoside analogues such as phenylpropenamide derivatives (Delaney et al., 2002), iminosugars (Mehta et al., 2001), heteroarylpyrimidines (Weber et al., 2002) have all been shown to be selective inhibitors of hepatitis B virus replication. These inhibitors do not target HBV reverse transcriptase but they prevent the encapsidation of viral pregenomic RNA. None of the non-nucleoside indole derivatives are reported as anti-HBV agent so far, although some indole derivatives have been found to be strong inhibitors of HCV and HIV.

In the framework of the above studies, we aimed to test some novel $\mathrm{N}-\mathrm{H}, \mathrm{N}$-substituted indole-2- and -3-carboxamides (Fig. 1) and $\mathrm{N}-\mathrm{H}$, $\mathrm{N}$-substituted indole-3-propanamide derivatives (Fig. 2), which were previously synthesized and reported as antioxidant agents (Bozkaya et al., 2007; Ölgen et al., 2007a, b), in order to identify their possible antimicrobial, antifungal and anti-HBV activities. In the present investigation, the in vitro activity of the compounds was determined by a disc diffusion method and the MIC values of the compounds were calculated by the tube dilution technique. Indole derivatives were also tested for their anti-HBV activity by in vitro replication of the HepAD38 cell line and the anti-HBV susceptibility test.

\section{Experimental}

\section{Disc diffusion method}

Antibacterial activity against Staphylococcus aureus, Bacillus subtilis, Escherichia coli, and antifungal activity against Candida albicans were investigated by the disc diffusion method (Tunçbilek et al., 1999). Mueller-Hinton agar (MHA, DIFCO, Detroit, MI, USA) was melted at $100^{\circ} \mathrm{C}$, and after cooling to $56^{\circ} \mathrm{C}$, it was poured into Petri plates of $9 \mathrm{~cm}$ diameter in quantities of $20 \mathrm{ml}$, and left on a flat surface to solidify. The surface of the medium was dried at $37^{\circ} \mathrm{C}$. After the culture of each bacterium and yeast strain was kept in Mueller-Hinton broth at $37^{\circ} \mathrm{C}$ for $18-24 \mathrm{~h}$ and diluted with Mueller-Hinton broth to $10^{5} \mathrm{cfu} / \mathrm{ml}$, they were pipetted into Mueller-Hinton agar plates prepared as described above. The surface of the medium was allowed to dry. The paper disc ( $8 \mathrm{~mm}$ in diameter) was soaked in $3000 \mu \mathrm{M}$ (in propylene glycol as a blank; it has no inhibition zone) compound and was applied to the surface of inoculated plates. After $18-24 \mathrm{~h}$ of incubation at $37^{\circ} \mathrm{C}$, the Petri plates were examined and the diameter of the growth inhibition zone around the paper disc was measured. The activity results of tested compounds and references are shown in Table I.

\section{Tube dilution technique}

The in vitro antimicrobial and antifungal activities of compounds were also tested by the tube dilution technique (Tunçbilek and Altanlar, 2006). This technique was followed to determine the 
MIC values of all synthesized compounds. Each of the test compounds and the standards (ampicillin, miconazole, and ciprofloxacin) was dissolved in $12.5 \%$ DMSO, at concentrations of $200-220 \mu \mathrm{g} /$ $\mathrm{ml}$. Further dilutions of the compounds and standards in the test medium were prepared at the required quantities of $100,50,25,12.5,6.25,3.125$, 1.56 , and $0.78 \mu \mathrm{g} / \mathrm{ml}$. Bacteria and fungal species were obtained from Microbiology Department, Faculty of Pharmacy, Ankara University, Turkey and Refik Saydam Health Institution of Health Ministry, Ankara, Turkey, namely Staphylococcus aureus (ATCC 25923), Bacillus subtilis (ATCC 6633), Escherichia coli (ATCC 23556), Candida albicans (ATCC 10145). The bacterial strains were maintained on MHA a medium for $24 \mathrm{~h}$ at $37^{\circ} \mathrm{C}$ and fungi were maintained on SDA (Sabouraud dextrose agar) for $2-5 \mathrm{~d}$ at $(25 \pm 1){ }^{\circ} \mathrm{C}$. The bacteria and fungi inocula were prepared by suspension in $9 \mathrm{ml}$ of sterile water for colonies from a culture on MHA and SDA medium. The cell density of each inoculum was adjusted in sterile water of a $0.5 \mathrm{Mc}$ Farland standard. The final inoculum size was $10^{5} \mathrm{cfu} / \mathrm{ml}$ and $10^{4} \mathrm{cfu} / \mathrm{ml}$ for the bacteria and fungi, respectively. Microbial inocula were added to the two-fold diluted samples, and each experiment in the antibacterial and antifungal assays was replicated twice. A set of tubes containing only inoculated broth was used as control. After incubation of the bacteria for $18-24 \mathrm{~h}$ at $(37 \pm 1)^{\circ} \mathrm{C}$ and of the fungi for $2-5 \mathrm{~d}$ at $(25 \pm 1){ }^{\circ} \mathrm{C}$, the last tube with no growth of microorganisms was recorded to represent the MIC value expressed in $\mu \mathrm{g} / \mathrm{ml}$.

In vitro replication of HepAD38 cell line and anti-HBV susceptibility testing of novel molecules

The in vitro replication ability of the HepAD38 cell line (was kindly gifted by Raymond F. Schinazi, Emory University, Atlanta, USA) was tested in the presence of the novel molecules synthesized. 24-Well plates were seeded with $5 \cdot 10^{4}$ HepAD38 cells in growth medium contaning DMEM/Ham's F12 supplemented with $10 \%(\mathrm{v} / \mathrm{v})$ heat-inactivated fetal calf serum, $100 \mathrm{IU} / \mathrm{ml}$ penicillin $/ 50 \mu \mathrm{g} / \mathrm{ml}$ streptomycin mix, $400 \mu \mathrm{g} / \mathrm{ml} \mathrm{G} 418$, and $0.3 \mu \mathrm{g} / \mathrm{ml}$ tetracycline. In order to initiate viral replication, growth medium was changed with assay medium by the withdrawal of tetracycline. Two days post seeding, cells were fed with fresh assay medium alone to test the replication efficiency or with assay medium containing increasing concentrations $(0.1,1,10$ and $100 \mu \mathrm{M})$ of the compounds. The supernatant of the cells fed with only fresh assay medium was collected every day during $5 \mathrm{~d}$, and the supernatant of the cells fed with the drugcontaining assay medium was collected at the end of the fifth day. Viral DNA extraction was performed using "QIAamp DNA Mini Kit" (Qiagen, Basel, Switzerland) according to the manufacturer's instructions. The HBV DNA was measured with a real-time PCR method using hybridization probes and "Fast Start DNA Hybridization Kit" (Roche Diagnostics, GmbH, Indianapolis, IN, USA) according to a previously published protocol (Bozkaya et al., 2005). Two independent experiments were performed for each drug. Lamivudine (3TC, 2',3'-dideoxy-3'-thiacytidine), whose antiHBV activity is well documented (Borgia and Gentile, 2006), was used as positive control.

\section{Results and Discussion}

All compounds (Figs. 1 and 2) were tested in vitro for their antimicrobial activity against Bacillus subtilis, Escherichia coli, Staphylococcus aureus using ampicillin and ciprofloxacin as a standard and for their antifungal activity against Candida albicans using miconazole as a standard. The compounds were dissolved in propylene glycol (PGG) at concentrations of $0.2-0.22 \mathrm{mg} / \mathrm{ml}$. PGG did not show any inhibitory effect on the growth of the test organisms. Table I shows the results of the in vitro activity determination by the disc diffissuion method (Tunçbilek et al., 1999). More propanamide derivatives have bigger inhibition zones than carboxamide derivatives, which represent their better activity. Moreover, the antimicrobial activity results obtained from this assay showed that all compounds and ampicillin are almost equally active against Staphylococcus aureus. Indoles substituted at position 3 with several benzyl groups were found more active against Bacillus subtilis than their congeners substituted at position 2. Comparison of the activity results between substituted phenyl- or substituted benzyl-containing indole carboxamides at either the 2- or 3-position showed that most of the substituted phenyl derivatives have higer activity. The $N$-unsubstituted indole propanamide compounds $\mathbf{2 7}$ and $\mathbf{2 8}$ are better inhibitors of Bacillus subtilis than the other nonsubstituted compounds at the 1-position. Activity patterns of the compounds against Escherichia coli 


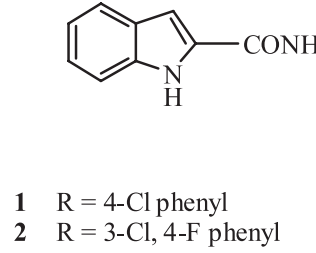

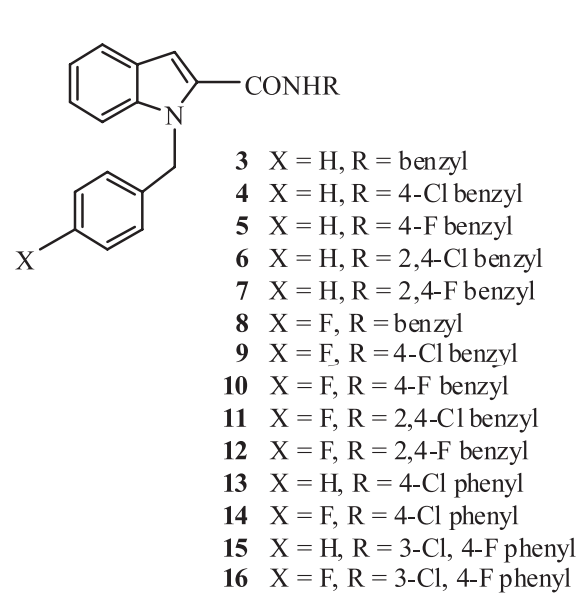

$3 \mathrm{X}=\mathrm{H}, \mathrm{R}=$ benzyl

$5 \mathrm{X}=\mathrm{H}, \mathrm{R}=4-\mathrm{F}$ benzyl

$6 \mathrm{X}=\mathrm{H}, \mathrm{R}=2,4-\mathrm{Cl}$ benzyl

$7 \mathrm{X}=\mathrm{H}, \mathrm{R}=2,4-\mathrm{F}$ benzyl

$8 \mathrm{X}=\mathrm{F}, \mathrm{R}=$ benzyl

$9 \mathrm{X}=\mathrm{F}, \mathrm{R}=4-\mathrm{Cl}$ benzyl

$10 \mathrm{X}=\mathrm{F}, \mathrm{R}=4-\mathrm{F}$ benzyl

$11 \mathrm{X}=\mathrm{F}, \mathrm{R}=2,4-\mathrm{Cl}$ benzyl

$13 \mathrm{X}=\mathrm{H}, \mathrm{R}=4-\mathrm{Cl}$ phenyl

$16 \mathrm{X}=\mathrm{F}, \mathrm{R}=3-\mathrm{Cl}$, 4-F phenyl

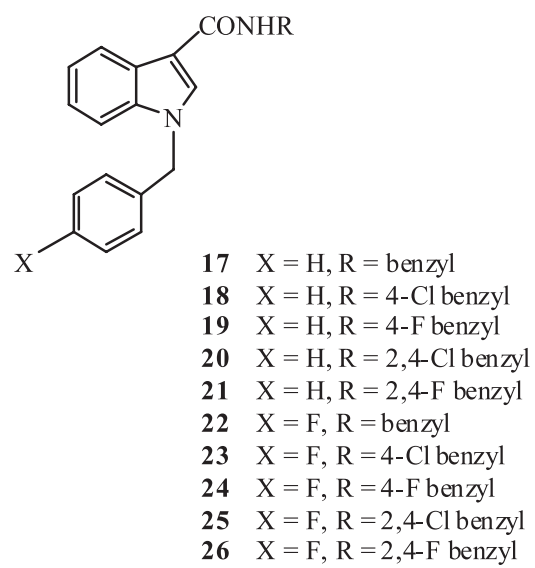

Fig. 1. $\mathrm{N}-\mathrm{H}$ and $\mathrm{N}$-substituted indole-2- and -3-carboxamide derivatives.
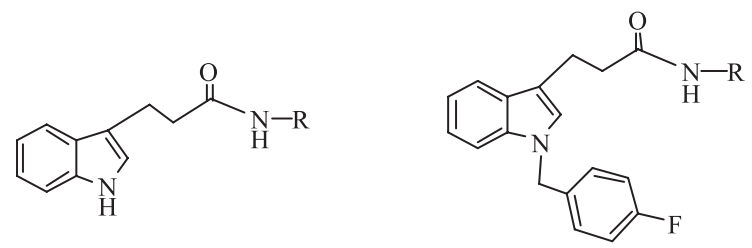

$\begin{array}{ll}\mathbf{2 7} & \mathrm{R}=4-\mathrm{Cl} \text { phenyl } \\ \mathbf{2 8} & \mathrm{R}=3-\mathrm{Cl} \text {, }-\mathrm{F} \text { phenyl } \\ \mathbf{2 9} & \mathrm{R}=4-\mathrm{Cl} \text { benzyl } \\ \mathbf{3 0} & \mathrm{R}=4-\mathrm{F} \text { benzyl } \\ \mathbf{3 1} & \mathrm{R}=2,4-\mathrm{Cl} \text { benzyl } \\ \mathbf{3 2} & \mathrm{R}=2,4-\mathrm{F} \text { benzyl }\end{array}$

Fig. 2. $\mathrm{N}-\mathrm{H}$ and $\mathrm{N}$-substituted indole-3-propanamide derivatives.

and Staphylococcus aureus were found slightly different. In this case, there was no correlation between the structure and activity of the compounds. $\mathrm{N}$-Substituted indole with halogen substituents of the benzamide ring at 3-position enhanced the antimicrobial activity more than their congeners substituted at 2-position. In addition, the $N$-unsubstituted compounds $\mathbf{1}$ and $\mathbf{2}$ with a halogensubstituted aniline side chain at 2-position showed higher activity against Candida albicans than the other $N$-unsubstituted congeners. In general, almost all $\mathrm{N}-\mathrm{H}$ and $\mathrm{N}$-substituted indole-2- and -3carboxamide derivatives showed a larger inhibition zone against Candida albicans than $\mathrm{N}-\mathrm{H}$ and $N$ - $p$-fluorobenzyl-substituted propanamide derivatives. We can assume that the carboxamide deriva- tives are better antifungal compounds than the propanamide derivatives.

The MIC values of the compounds were determined by the two-fold serial dilution technique for the antibacterial and antifungal assay in MuellerHinton broth and Sabouraud dextrose agar, respectively (Tunçbilek and Altanlar, 2006). The activity results are shown in Table II. Some indole derivatives, which showed a bigger inhibition zone by the disc diffusion method, were picked to determine their MIC values. No compound was found active against Staphylococcus aureus, Bacillus subtilis and Escherichia coli compared with ciprofloxacin. The tested compounds showed slight inhibition in the range $6.56-13.12 \mu \mathrm{g} / \mathrm{ml}$ against Candida albicans. In general, the activity results reveal that the small structural differences can have a great influences on the antimicrobial activity. The same substitution pattern on different positions of indole-2- and -3-carboxamide may lead to a different role in the inhibition of microorganisms. Consequently, the antimicrobial and antifungal screening of indole carboxamide and propanamide derivatives, and moreover information obtained from literature give us a new direction to design a concept of new indole derivatives. Especially, it was found that most of our compounds are more active as antifungals than as antibacterials, which could guide us to design new lead antifungal indole derivatives.

Some simple indole derivatives with mixed antifungal and antibacterial activities were converted by Whitehead and Whitesitt (1974) to antibacterial 
Table I. In vitro antibacterial and antifungal activity results ${ }^{\mathrm{a}}$ of $\mathbf{1 - 3 8}$, which were obtained by the disc diffusion method.

\begin{tabular}{|c|c|c|c|c|c|c|c|c|c|}
\hline Compound & $S A$ & $B S$ & $E C$ & $C A$ & Compound & $S A$ & $B S$ & $E C$ & $C A$ \\
\hline $\mathbf{1}$ & 20 & 19 & 11 & 20 & 21 & 22 & 16 & 17 & 18 \\
\hline 2 & 17 & 19 & 11 & 20 & 22 & 20 & 15 & 14 & 18 \\
\hline 3 & 20 & 10 & 15 & 10 & 23 & 20 & 17 & 15 & 18 \\
\hline 4 & 20 & 10 & 17 & 15 & 24 & 20 & 15 & 14 & 20 \\
\hline 5 & 22 & 9 & 17 & 15 & 25 & 20 & 16 & 15 & 20 \\
\hline 6 & 20 & 10 & 17 & 15 & 26 & 22 & 17 & 18 & 20 \\
\hline 7 & 15 & 10 & 10 & 15 & 27 & 17 & 18 & 10 & 15 \\
\hline 8 & 18 & 10 & 10 & 15 & 28 & 20 & 20 & 10 & 17 \\
\hline 9 & 18 & 10 & 10 & 17 & 29 & 15 & 15 & 10 & 12 \\
\hline 10 & 20 & 10 & 10 & 17 & 30 & 17 & 15 & 10 & 12 \\
\hline 11 & 20 & 10 & 13 & 20 & 31 & 20 & 17 & 17 & 15 \\
\hline 12 & 20 & 10 & 15 & 19 & 32 & 25 & 10 & 15 & 15 \\
\hline 13 & 20 & 19 & 13 & 15 & 33 & 20 & 10 & 17 & 14 \\
\hline 14 & 20 & 15 & 15 & 15 & 34 & 20 & 15 & 15 & 15 \\
\hline 15 & 20 & 17 & 13 & 17 & 35 & 22 & 12 & 10 & 10 \\
\hline 16 & 20 & 14 & 15 & 15 & 36 & 22 & 12 & 10 & 10 \\
\hline 17 & 15 & 10 & 15 & 20 & 37 & 20 & 14 & 12 & 10 \\
\hline 18 & 20 & 15 & 17 & 20 & 38 & 20 & 14 & 12 & 10 \\
\hline 19 & 20 & 15 & 15 & 18 & Ampicillin & 20 & 10 & 10 & \\
\hline 20 & 20 & 15 & 15 & 18 & Miconazole & & & & 10 \\
\hline
\end{tabular}

a Growth inhibition zone diameter $(\mathrm{mm})$.

SA, Staphylococcus aureus; BS, Bacillus subtilis; EC, Escherichia coli; CA, Candida albicans.

\begin{tabular}{|c|c|c|c|c|}
\hline \multirow[t]{2}{*}{ Compound } & \multicolumn{4}{|c|}{$\operatorname{MIC}[\mu \mathrm{g} / \mathrm{ml}]$} \\
\hline & $\begin{array}{c}\text { Staphylococcus } \\
\text { aureus }\end{array}$ & $\begin{array}{l}\text { Bacillus } \\
\text { subtilis }\end{array}$ & $\begin{array}{l}\text { Escherichia } \\
\text { coli }\end{array}$ & $\begin{array}{l}\text { Candida } \\
\text { albicans }\end{array}$ \\
\hline 1 & 105.0 & 52.5 & 52.5 & 13.12 \\
\hline 5 & 105.0 & 52.5 & 52.5 & 13.12 \\
\hline 13 & 110.0 & 110.0 & 110.0 & 6.87 \\
\hline 18 & 105.0 & 52.5 & 52.5 & 6.56 \\
\hline 21 & 105.0 & 52.5 & 52.50 & 6.56 \\
\hline 26 & 105.0 & 52.5 & 52.5 & 6.56 \\
\hline 28 & 110.0 & 27.5 & 55.0 & 6.87 \\
\hline 32 & 100.0 & 25.0 & 50.0 & 12.5 \\
\hline Ciprofloxacin & 3.12 & 1.56 & 3.13 & \\
\hline Ampicillin & 1.56 & 1.56 & 12.5 & \\
\hline Miconazole & & & & 0.41 \\
\hline
\end{tabular}

Table II. In vitro antimicrobial and antifungal activities of some indole derivatives (MIC). compounds by introducing an appropriate diarylmethyl substituent. These investigators also increased the antifungal activity of 5-bromoindole $2-25$ times by adding the diphenylmethyl group to the 3-position. The compound 5-bromoindole inhibited six of the fungal species and was considered as an effective antifungal agent of the simple indoles. Inspired by these studies, instead of an amide group, insertion of a halogen-substituted aromatic ring at 2- and 3-position of indole and concurrent substitutions at position 5 of the indole with halogens especially with bromine are under- way to test these modifications for biological activity.

Indole derivatives were also tested for the in $v i$ tro replication of the HepAD38 cell line, and the anti-HBV susceptibility was compared with that of lamivudine. The $\mathrm{IC}_{50}$ values of all compounds were found $>1000 \mu \mathrm{M}$ against $\mathrm{HBV}$ and the one for lamivudine was detected as $0.29 \mu \mathrm{M}$ at the same reaction conditions. It is known that the treatment of chronic hepatitis B infection is based on the suppression of viral replication. To date, this is achieved by either interferon- $\alpha$ or nucleo- 
side analogues. There is no certain structure for non-nucleoside analogues useful as inhibitors of HBV. Most of them were developed to block the proper formation of nucleocapsid of HBV (Wen et al., 2003), and they showed potent inhibition of HBV replication in vitro and in vivo. Conclusion from findings in literature suggests that to identify a new lead by randomly compounds or from preselected chemical libraries, determination of antiviral selectivity and specificity of newly discovered active compounds are still practical tools to discover new anti-HBV drugs. Although several therapeutic options now exist to cure HBV infection,

Beaulieu P. L., Gillard J., Bykowski D., Brochu C., Dansereau N., Duceppe J.-S., Hache B., Jakalian A., Lagace L., La Plante S., Mcercher G., Moreau E., Perreault S., Stammers T., Thauvette L., Warrington J., and Kukolj G. (2006), Improved replicon cellular activity of non-nucleoside allosteric inhibitors of $\mathrm{HCV}$ NS5B polymerase: From benzimidazole to indole scaffolds. Bioorg. Med. Chem. Lett. 16, 4987-4993.

Bhovi M. G. and Gadaginamath G. S. (2005), 1,3-Dipolar cycloaddition reactions: Synthesis and antimicrobial activity of novel 1-triazolylindole and 1-triazolylbenz[g]indole derivatives. Indian J. Chem. 44B, 1068-1073.

Borgia G. and Gentile I. (2006), Treating chronic hepatitis B: today and tomorrow. Curr. Med. Chem. 13, 2839-2855.

Bozkaya H., Yurdaydin C., and Idilman R. (2005), Lamivudine treatment in $\mathrm{HBeAg}$-negative chronic hepatitis B patients with low level viraemia. Antiviral Ther. 10, 319-325.

Bozkaya P., Olgen S., Çoban T., and Nebioğlu D. (2007), Synthesis of $N$-substituted indole-2-carboxamides and investigation of their biochemical responses against free radicals. J. Enzym. Inhib. Med. Chem. 22, 319325.

Conte I., Ercolani C., Narjes F., Pompei M., Rowley M., and Stansfield I. (2006), Preparation of tetracyclic indole derivatives as antiviral agents. Patent WO 2006046030.

Delaney W. E., Edwards R., Colledge D., Shaw T., Furman P., Painter G., and Locarnini S. (2002), Phenylpropanamide derivatives AT-61 and AT-130 inhibit replication of wild-type and lamivudine-resistance strains of hepatitis B virus in vitro. Antimicrob. Agents Chemother. 46, 3057-3060.

Donawade D. S. and Gadaginamath G. S. (2005), Some electrophilic substitution reactions on 1-substituted-3acetyl/carbethoxy-5-hydroxy-2-methylindole and antimicrobial activity of these new indole derivatives. Indian J. Chem. 44B, 1679-1685.

Gadaginamath G. S. and Kavali R. R. (1999), Synthesis and antimicrobial activity of novel $4 H$-pyrano[2,3-f]indole derivatives. Indian J. Chem. 38B, 178-182. the poor response rate and the development of resistant mutants highlight the need for alternative drugs. Since some indole derivatives exhibited some antiviral activity and organized serendipity can still play an important role to discover new drug candidates, there is a chance to have active indole derivatives against $\mathrm{HBV}$ infections in future.

\section{Acknowledgements}

This work was partially supported by a grant from the Turkish Scientific and Technical Research Institute (106S127 SBAG-HD-141).

Harper S., Avolio S., Pacini B., Di Filippo M., Altamura S., Tomei L., Paonessa G., Di Marco S., Carfi A., Giuliano C., Padron J., Bonelli F., Migliaccio G., De Francesco R., Laufer R., Rowley M., and Narjes F. (2005), Potent inhibitors of subgenomic hepatitis $\mathrm{C}$ virus RNA replication through optimization of indole- $N$ acetamide allosteric inhibitors of the viral NS5B polymerase. J. Med. Chem. 48, 4547-4557.

Jiang T., Kuhen K. L., Wolff K., Yin H., Bieza K., Caldwell J., Bursulaya B., Tuntland T., Zhang K., Karanewsky D., and He Y. (2006), Design, synthesis and biological evaluations of novel oxindoles as HIV-1 non-nucleoside reverse transcriptase inhibitors. Bioorg. Med. Chem. Lett. 16, 2109-2112.

Macchia M., Manera C., Nencetti S., Rossello A., Broccali G., and Limonta D. (1996), Synthesis and antimicrobial activity of benzo[a]dihydrocarbazole and benzotetrahydrocyclohept[1,2-b]indole derivatives. Farmaco 51, 75-78.

Malesani G., Chiarelotto G., Dallacqua F., and Vedali D. (1975), Antimicrobial properties of some 3-acyl-4,7disubstituted indoles. Farmaco 30, 137-146.

Mehta A., Carrouee S., Conyers B., Jordan R., Butters T., Dwek R. A., and Block T. M. (2001), Inhibition of hepatitis B virus DNA replication by iminosugar without the inhibition of the DNA polymerase: therapeutic implications. Hepatology 33, 1488-1495.

Mehta D. S., Sikotra K. H., and Shah V. H. (2005), Synthesis and biological screening of some new novel indole derivatives. Indian J. Chem. 44B, 2590-2597.

Ölgen S., Kılıç Z., Ada A. O., and Çoban T. (2007a), Synthesis and antioxidant properties of novel $\mathrm{N}-\mathrm{H}$ and $N$-substituted propanamide derivatives. Arch. Pharm. 340, 140-146.

Ölgen S., Kılıç Z., Ada A. O., and Çoban T. (2007b), Synthesis and evaluation of novel $\mathrm{N}-\mathrm{H}$ and $\mathrm{N}$-substituted indole-2- and -3-carboxamide derivatives as possible antioxidant agents. J. Enzym. Inhib. Med. Chem. 22, 457-462.

Romero D. L., Olmsted R. A., Poel T. J., Morge R. A., Biles C., Keiser B. J., Kopta L. A., Friis J. M., Hosley J. D., Stefanski K. J., Wishka D. G., Evans D. B., Mor- 
ris J., Stehle R. G., Sharma S. K., Yagi Y., Voorman R. L., Adams W. J., and Tarpley W. G. (1996), Delaviridine/ateviridine resistance HIV-1. 2. Identification of (alkylamino)piperidine-containing bis(heteroaryl)piperazines as broad spectrum reverse transcriptase inhibitors. J. Med. Chem. 39, 3769-3789.

Slater M. J., Baxter R., Bonser R. W., Cockerill S., Gohil K., Robinson E., Randall R., Yeates C., Snowden W., and Walters A. (2001), Synthesis of $N$-alkyl substituted indolocarbazoles as potent inhibitors of human cytomegalovirus replication. Bioorg. Med. Chem. Lett. 11, 1993-1995.

Tan T. M. C., Chen Y., Kong H., Bai J., Li Y., Lim S. G., Ang T. H., and Lam Y. (2006), Synthesis and the biological evaluation of 2-benzenesulfonylalkyl-5-substituted-sulfonyl-[1,3,4]-oxadiazoles as potential antihepatitis B virus agents. Antiviral Res. 71, 7-14.

Tsotinis A., Varvaresou A., Calogeropoulou T., SiatraPapastaikoudi T., and Tiligada A. (1997), Synthesis and antimicrobial evaluation of indole containing derivatives of 1,3,4-triazole and their open-chain counterparts. Arzneim.-Forsch./Drug Res. 47, 307-310.

Tunçbilek M. and Altanlar N. (2006), Synthesis of new 3(substituted phenacyl)-5-[3'-(4H-4-oxo-1-benzopyran2-yl)-benzylidene]-2,4-thiazolidinediones and their antimicrobial activity. Arch. Pharm. Chem. Life Sci. 339, 213-216.

Tunçbilek M., Bozdağ O., Ayhan-Kılcıgil G., Altanlar N., Büyükbingöl E., and Ertan R. (1999), Synthesis and antimicrobial activity of some new flavonyl oxime ether derivatives. Arzneim.-Forsch./Drug Res. 49, $853-857$.
Varvaresou A., Tsantili-Kakoulidou A., Siatra-Papastaikoudi T., and Tiligada E. (2000), Synthesis and biological evaluation of indole containing derivatives of thiosemicarbazide and their cyclic 1,2,4-triazole and 1,3,4-thiadiazole analogs. Arzneim.-Forsch./Drug Res. 50, $48-54$.

Weber O., Schlemmer K. H., Hartmann E., Hagelschuer I., Paessens A., Graef E., Deres K., Goldmann S., Niewoehner U., Stoltefuss J., Haebich D., Ruebsamen-Waigmann H., and Wohlfeil S. (2002), Inhibition of human hepatitis B virus (HBV) by a novel nonnucleoside compound in a transgenic mouse model. Antiviral Res. 54, 68-78.

Wen Y.-M., Lin X., and Ma Z.-M. (2003), Exploring new potential targets for anti-hepatitis B virus drugs. Curr. Drug Targets 3, 241-246.

Whitehead C. W. and Whitesitt A. A. (1974), Effects of lipophilic substituents on some biological properties of indoles. J. Med. Chem. 17, 1298-1304.

Williams T. M., Ciccarone T. M., MacTough S. C., Rooney C. S., Balani S. K., Condra J. H., Emini E. A., Goldman M. E., Greenlee W. J., Kauffman L. R., O'Brien W. J., Sardana V. V., Schleif W. A., Theoharides A. D., and Anderson P. S. (1993), 5-Chloro-3(phenylsulfonyl)indole-2-carboxamide: A novel, nonnucleoside inhibitor of HIV-1 reverse transcriptase. J. Med. Chem. 36, 1291-1294.

Ying C., De Clercq E., and Neyts J. (2003), Selective inhibitors of hepatitis B virus replication. Curr. Med. Chem. 2, 227-240.

Zhao Y., Hong W., Chai H., Dong J., and Gong P. (2004), Synthesis and anti-influenza virus activity of ethyl-6bromo-5-hydroxy- $1 H$-indole-3-carboxylate derivatives. Zhongguo Yaowu Huaxue Zazhi 14, 219-224. 